\title{
Creating a Predictable Implant Outcome Using a Self- Designed Surgical Guide- A Case Report
}

\author{
Stephanie Aldrich* \\ Doctor in Ohio, Akron Dental Concepts, USA
}

Submission: April 18, 2018; Published: May 24, 2018

*Corresponding author: Stephanie Aldrich, Doctor in Ohio, Akron Dental Concepts, USA, Tel: +1-330-666-7440; Email: docaldrich@gmail.com

\begin{abstract}
Being a general dentist has its advantage over an oral surgeon or a periodontist when it comes to implant placement for the main reason of having the knowledge of the final restoration placement. When one plans an implant surgery with the end restoration in mind, creating a predictable result follows. Technology has made it easier to combine digital radiography with stent-forming software to make implant surgery more efficient and profitable.
\end{abstract}

Keywords: Implants; Self-designed surgical guide; Blue Sky Bio; Biohorizons; Legacy 4; Implant Direct

\section{Introduction}

There are only two big considerations when planning dental implant treatment. The first- is there enough strong bone to support the implant? The second- can I restore the implant successfully after it's healed? According to the American Academy of Implant Dentistry (AAID) more than three million Americans have implants and that number is growing by 500,000 a year Only $10 \%$ of general US dentists place their own implants [1]. If a restorative general dentist is not involved with the treatment planning phase of the implant surgery, difficulty in the restorative phase can be experienced.

More consideration should be given to the restorative phase of implant treatment during the surgery planning phase. This is the main reason general dentists should consider placing the implants themselves. If experience in doing the surgery is a consideration, learning how to plan and fabricate one's own surgical guide can help create a predictable and successful outcome. In this case report, I present a clinical case of a guided implant surgery in a 57 year old female replacing her maxillary second premolar.

\section{Case Report}

A 56 year old healthy Caucasian female came into my office with a left maxillary premolar toothache. An intraoral periapical radiograph was taken and clinically I could see the tooth was fractured and loose going up through the central groove, cutting the tooth in half subgingivally. Deeming this tooth hopeless, I gave her treatment options including but not limited to a bridge or bone grafting, implant, and crown. The patient had no restorations on the first premolar or molar, so the bone grafting, implant, and crown seemed to be the best choice for treatment.The patient was anesthetized with $2 \%$ lidocaine $w / 1: 100,000$ epi and the tooth was atraumatically extracted. After debriding and irrigating socket with sterile saline, an Osteogen collagen bone grafting plug was placed into the four-walled boney defect and the site was sutured. The sutures were removed after 10 days and the site was allowed to heal. The patient wanted to wait to do the implant for financial reasons (Figure 1) 12 months later, the patient returned to the office for a Cone Beam Computed Tomography (CBCT) image and a digital stereolithography (STL) impression so that the implant surgical guide could be planned.

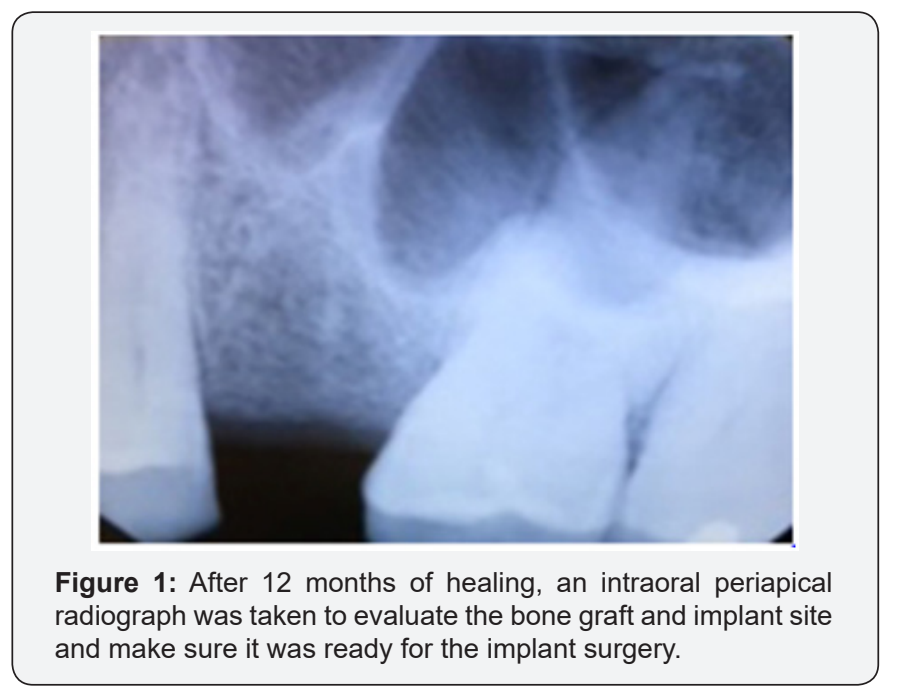

I used Blue Sky Bio software and merged the CBCT image with the STL digital impression. With this combined picture, I could then look at how the restoration and implant would look in comparison to the available bone and the location of the sinus and chose the correct size implant (Figure 2a). The guide was designed and the files sent to Digi3dworks for fabrication (Figure $2 b$ ). 


\section{Advances in Dentistry \& Oral Health}

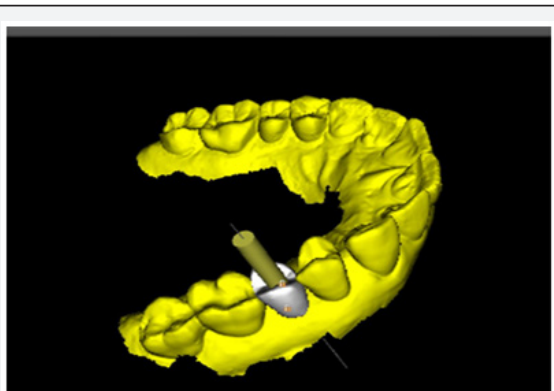

Figure 2a: The STL digital file was used to evaluate what the final restoration would look like with the planned implant.

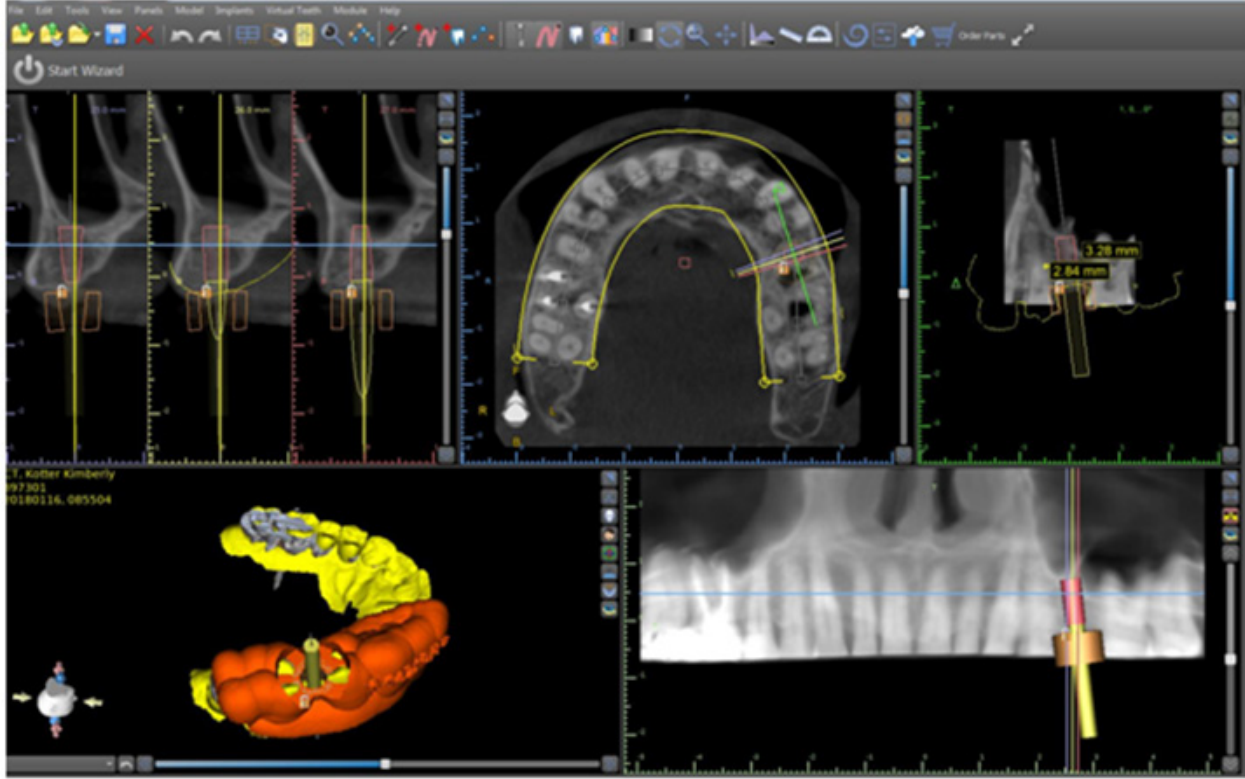

Figure 2b: Blue Sky Bio Software was used to plan the implant angulation and depth and then the surgical guide was designed.

Photos were taken pre-surgery (Figures $3 \& 4$ ). The patient was anesthetized with $2 \%$ lidocaine w/1:100,000 epi. A conservative full thickness flap was done and the guide was placed. The pilot drill was used at 1200 RPM with sterile saline irrigation and after verification of the angle with the guide pin, the osteotomy was widened using the Biohorizons surgical guide kit. We stopped short two width sizes and placed the $4.2 \mathrm{~mm} \times 8 \mathrm{~mm}$ Implant Direct Legacy 4 implant at $35 \mathrm{Ncm}$ (Figures $5 \& 6$ ). A radiograph and CBCT image were taken to verify placement (Figures 7 \& 8). The abutment was removed, a cover screw was placed, and covered with tissue and sutures. An antibiotic was given and the patient dismissed.

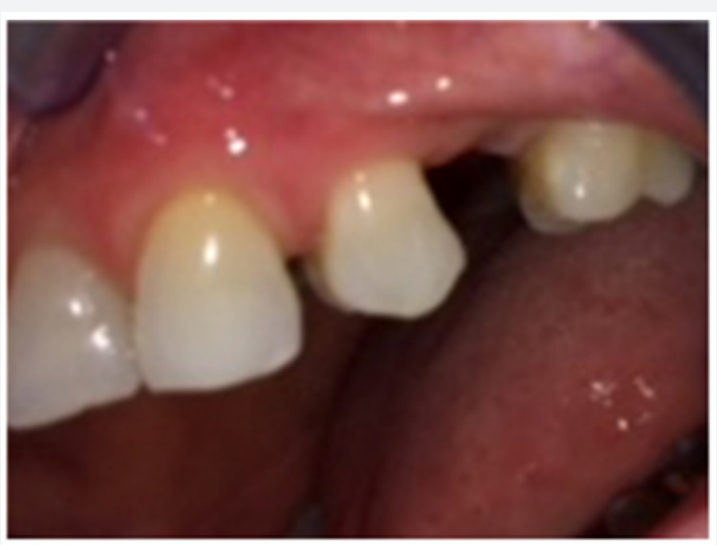

Figure 3: Pre-op lateral photo of implant site. 


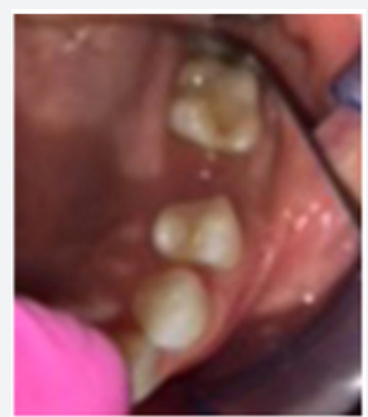

Figure 4: Pre-op lateral photo of implant site.

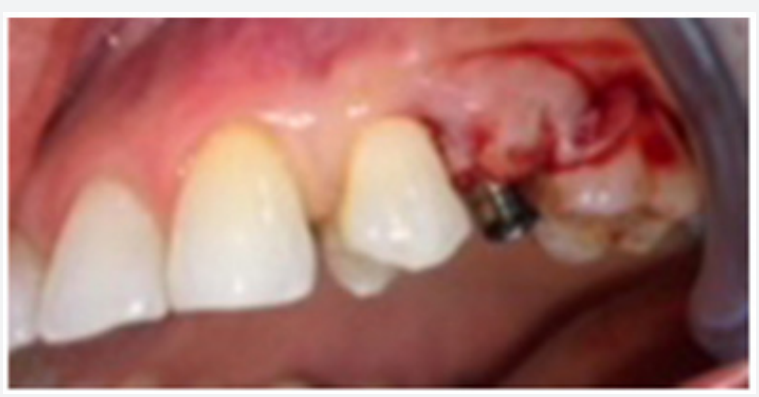

Figure 5: Pre-op lateral photo of implant site.

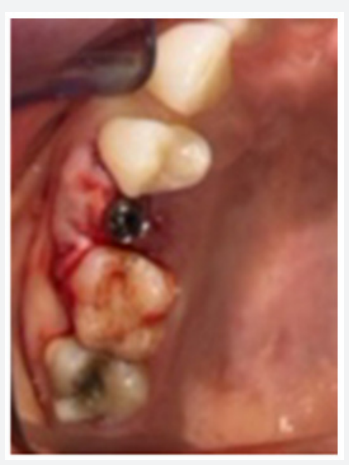

Figure 6: Post-surgical occlusal photo of implant placement.

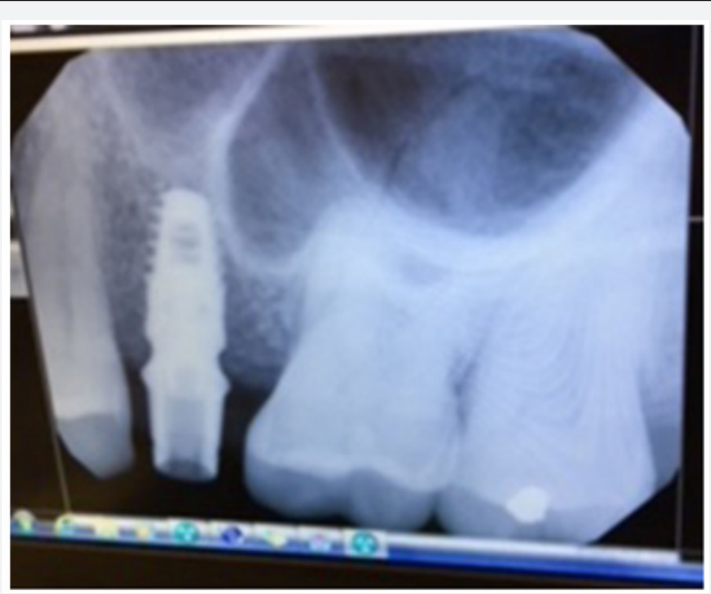

Figure 7: Intraoral periapical radiograph of implant placement. 


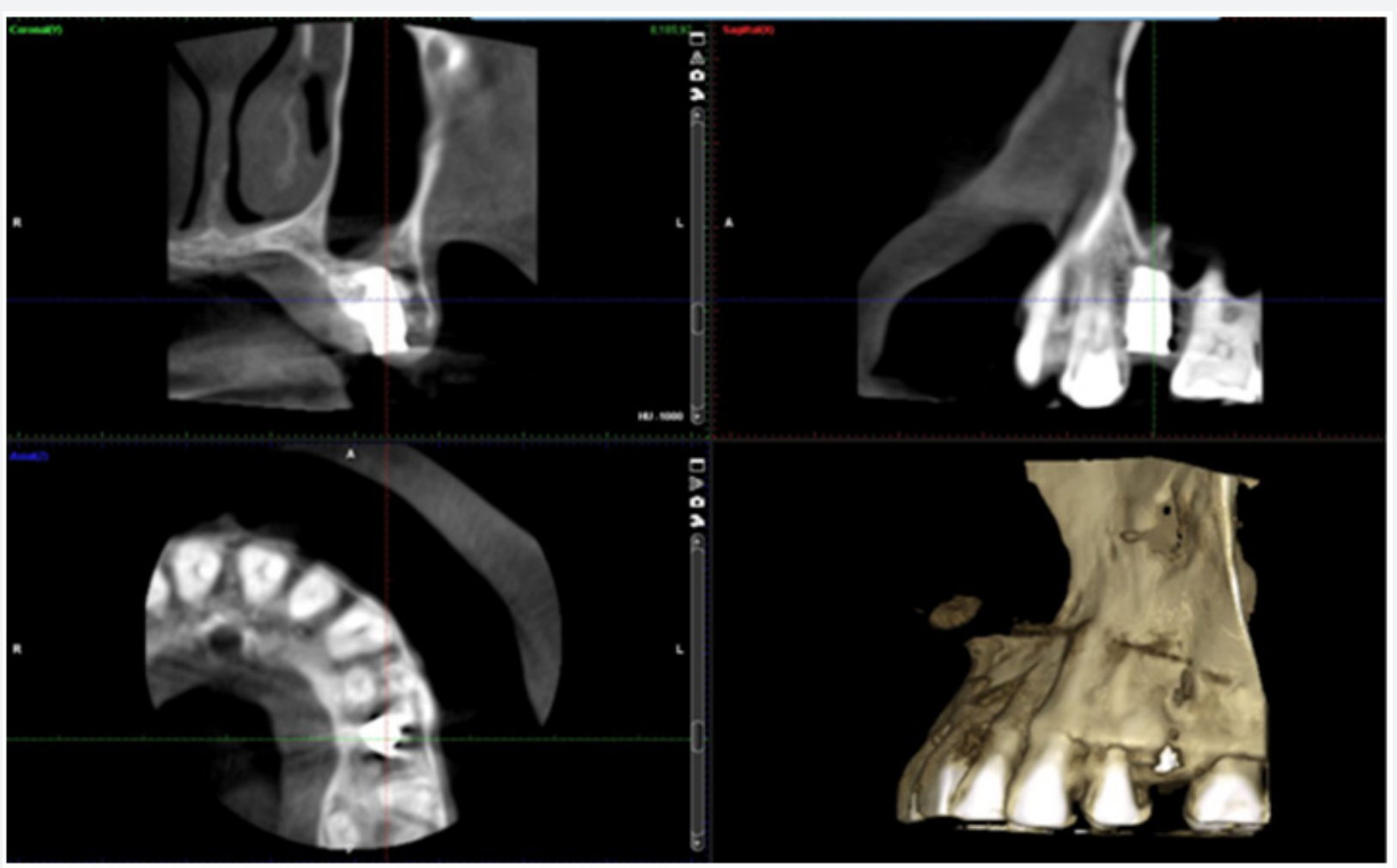

Figure 8: CBCT with lateral, sagittal, and occlusal view of implant placement.

\section{Discussion}

With the invention of custom and angled abutments, it has become easier to restore implants that have angles that aren't "ideal". However, there are still limits to this and how much occlusal force is being applied to the implant's axis. A general dentist has an advantage over a periodontist or oral surgeon when it comes to implant planning because he/she understands what the final restoration should look like and can plan the beginning surgical stage with the restoration end stage in mind.

Using a surgical guide can also make the process more efficient and predictable. According to Cristache [2] the accuracy of using a CBCT image and an STL digital impression is within $1 \mathrm{~mm}$ of the planned outcome and the surgical outcome. Following implant planning guidelines discussed by Shah [3] \& Shenoy [4] 1.5 to $2 \mathrm{~mm}$ of distance between implants and adjacent teeth allows for any discrepancy of the surgical guide and the final implant placement. In this case report, there was more limited space occlusally due to mesial drifting of the maxillary first molar allowing for a greater space between the implant body and the roots of the adjacent teeth. This space gave me a good "safety" zone to work with. Placing bone grafting, choosing the proper implant size for the space involved, and designing my own surgical guide allowed me to have a predictable surgery that took about 30 minutes from start to completion. More general dentist should consider designing their own surgical guides and doing the surgeries themselves.

\section{References}

1. AAID.com/about/Press_Room_Implants_FAQ.html

2. Corina Cristache, Silviu Gurbanescu (2017) Accuracy Evaluation of a Stereolithographic Surgical Template for Dental Implant Insertion Using 3D Superimposition Protocol. International Jour of Dent p. 9.

3. Shah KC, Lum MG (2008) Treatment Planning for Single Tooth Implant Restoration. General Considerations and Pretreatment Evaluation. J Calif Dent Assoc 36(11): 827-834.

4. Shenoy VK (2012) Single Tooth Implants: Pretreatment Considerations and Pretreatment Evaluation. J Interdiscip Dentistry 2(3): 149-157. 
This work is licensed under Creative Commons Attribution 4.0 License DOI: 10.19080/ADOH.2018.09.555755

\section{Your next submission with Juniper Publishers} will reach you the below assets

- Quality Editorial service

- Swift Peer Review

- Reprints availability

- E-prints Service

- Manuscript Podcast for convenient understanding

- Global attainment for your research

- Manuscript accessibility in different formats

( Pdf, E-pub, Full Text, Audio)

- Unceasing customer service

Track the below URL for one-step submission https://juniperpublishers.com/online-submission.php 